\title{
Impact of wound edge protection devices on surgical site infection after laparotomy: multicentre randomised controlled trial (ROSSINI Trial)
}

Thomas D Pinkney senior lecturer and consultant colorectal surgeon ${ }^{12}$, Melanie Calvert reader in epidemiology ${ }^{13}$, David C Bartlett specialist registrar ${ }^{1}$, Adrian Gheorghe doctoral researcher ${ }^{3}$, Val Redman trial manager ${ }^{3}$, George Dowswell research fellow ${ }^{13}$, William Hawkins consultant upper gastrointestinal surgeon ${ }^{1}$, Tony Mak assistant professor colorectal surgery ${ }^{1}$, Haney Youssef consultant colorectal surgeon ${ }^{1}$, Caroline Richardson specialist registrar ${ }^{1}$, Steven Hornby specialist registrar ${ }^{1}$, Laura Magill colorectal trial team leader ${ }^{14}$, Richard Haslop trial manager ${ }^{3}$, Sue Wilson professor of clinical epidemiology ${ }^{13}$, Dion Morton professor of surgery ${ }^{124}$, on behalf of the West Midlands Research Collaborative and the ROSSINI Trial Investigators

${ }^{1}$ West Midlands Research Collaborative, Old Queen Elizabeth Hospital, Edgbaston, Birmingham, UK; ${ }^{2}$ Academic Department of Surgery, University of Birmingham, Birmingham, UK; ${ }^{3}$ Primary Care Clinical Sciences, University of Birmingham, Birmingham, UK; ${ }^{4}$ Birmingham Clinical Trials Unit, University of Birmingham, Birmingham, UK

\begin{abstract}
Objective To determine the clinical effectiveness of wound edge protection devices in reducing surgical site infection after abdominal surgery.

Design Multicentre observer blinded randomised controlled trial.

Participants Patients undergoing laparotomy at 21 UK hospitals.

Interventions Standard care or the use of a wound edge protection device during surgery.
\end{abstract}

Main outcome measures Surgical site infection within 30 days of surgery, assessed by blinded clinicians at seven and 30 days and by patient's self report for the intervening period. Secondary outcomes included quality of life, duration of stay in hospital, and the effect of characteristics of the patient and operation on the efficacy of the device.

Results 760 patients were enrolled with 382 patients assigned to the device group and 378 to the control group. Six patients in the device group and five in the control group did not undergo laparotomy. Fourteen patients, seven in each group, were lost to follow-up. A total of 184 patients experienced surgical site infection within 30 days of surgery, $91 / 369(24.7 \%)$ in the device group and 93/366 (25.4\%) in the control group (odds ratio $0.97,95 \%$ confidence interval 0.69 to $1.36 ; P=0.85$ ). This lack of benefit was consistent across wound assessments performed

Correspondence to:TD Pinkney thomas.pinkney@uhb.nhs.uk

Video on bmj.com (see also http://bmj.com/video)

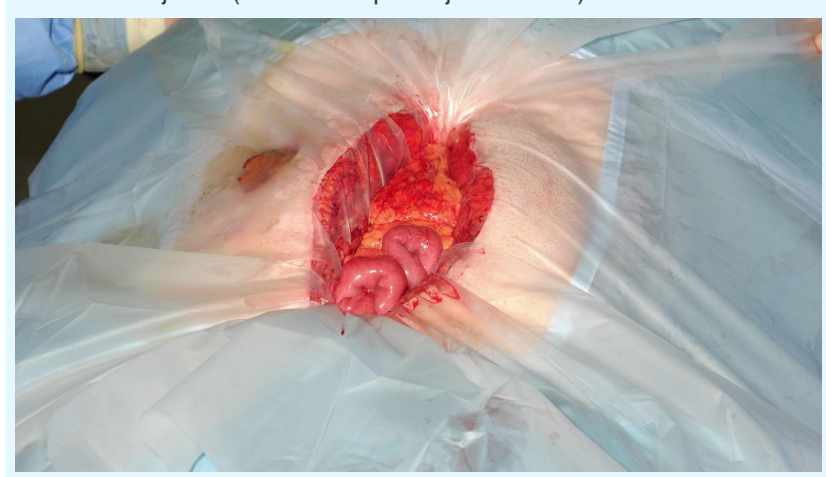


by clinicians and those reported by patients and across all secondary outcomes. In the secondary analyses no subgroup could be identified in which there was evidence of clinical benefit associated with use of the device.

Conclusions Wound edge protection devices do not reduce the rate of surgical site infection in patients undergoing laparotomy, and therefore their routine use for this role cannot be recommended.

Trial registration Current Controlled Trials ISRCTN 40402832

\section{Introduction}

Surgical site infection is one of the most common postoperative complications, occurring in at least $5 \%$ of all patients undergoing surgery and $30-40 \%$ of patients undergoing abdominal surgery, depending on the level of contamination. ${ }^{12}$ Development of a surgical site infection has a large impact on mortality and morbidity as well as healthcare costs. ${ }^{34}$ In the United Kingdom, length of stay in hospital is typically doubled and additional costs per patient of between $£ 814$ and $£ 10523$ (€950 (\$1237) and $€ 12300$ ( $\$ 16000)$ ) have been estimated, the variability depending on the type of surgery and the severity of the infection..$^{5-7}$ The ancillary costs from time off work, reduced health related quality of life, dissatisfaction in patients, and litigation costs for the healthcare provider have been explored less extensively, but the little evidence available confirms a detrimental effect. ${ }^{8}$

As most infections are the result of wound contamination by endogenous bacteria from the patient's skin, mucous membranes, or hollow viscera, the concept of using a physical barrier to cover the cut edges of the wound has been revisited by surgeons many times over the past half century. This protection can take the form of a wound edge protection device or "wound guard" that is inserted into the wound for the duration of the operation. There are several different devices on the market but they have the same basic design — a semirigid plastic ring placed into the abdomen through the laparotomy wound to which an impervious drape is circumferentially attached. This plastic drape comes up and out of the wound on to the skin surface, thus protecting the cut edges of the wound (fig 1) $\Downarrow$. Wound edge protection devices create a physical barrier between the abdominal wound edges and viscera, visceral contents, contaminated instruments, and gloves, thereby reducing accumulation of endogenous and exogenous bacteria on the wound edges. There have been six single centre and one multicentre trial, totalling around 1300 patients, which showed benefit from the use of a device and reporting a reduction in infections from $12-25 \%$ down to as low as zero in some series. ${ }^{9-15}$ Despite this their use is not discussed in the current UK clinical guidelines and they have not become established in routine clinical practice.

We assessed the clinical effectiveness of wound edge protection devices in reducing rates of infection at the site of surgery in patients undergoing open abdominal surgery to evaluate the impact on patients' health related quality of life and length of hospital stay. We also carried out a cost effectiveness analysis, which will be reported elsewhere.

\section{Methods}

\section{Study design and patients}

The ROSSINI (Reduction Of Surgical Site Infection using a Novel Intervention) trial was a prospective, multicentre, observer blinded, randomised controlled trial with stratification according to baseline infection risk. ${ }^{16}$ It was conducted from February
2010 to January 2012 at 21 National Health Service (NHS) hospitals across the UK.

This investigator initiated trial was conceived by the West Midlands Research Collaborative, a trainee led surgical research group who designed, disseminated, and managed the trial in conjunction with the Primary Care Clinical Research and Trials Unit and the Birmingham Clinical Trials Unit at the University of Birmingham.

Patients aged over 18 undergoing laparotomy for any surgical indication through any major incision in both elective and emergency settings were eligible for enrolment. Laparoscopic or laparoscopic assisted procedures were excluded, as were patients who had undergone a previous laparotomy within three months.

\section{Randomisation and masking}

Enrolled patients were randomly assigned through a concealed centralised secure web based system in a 1:1 ratio to either the control arm (standard intraoperative care) or the intervention arm (standard intraoperative care plus use of a wound edge protection device during the intra-abdominal part of the operation). Randomisation was performed when the patient was in the anaesthetic room immediately before surgery by using a secure online system provided by the University of Birmingham. To help match the two arms, randomisation was stratified according to the urgency of surgery, likelihood of opening a viscus, and likelihood of creating a stoma, with the use of a minimisation procedure. The in theatre surgical team were aware of arm allocation but only after induction of anaesthesia. No information about arm allocation was recorded in the clinical or operation notes, and the patient, ward staff, and clinicians undertaking the reviews of postoperative wounds were fully blinded to the group assignments.

Surgeons were free to undertake their other usual intraoperative interventions if they wanted, including their choice of antibiotic, skin preparation agent, use of adhesive incise drapes, and/or towels on the wound edges; these details were prospectively recorded and formed part of a planned secondary analysis. The device used (3M Steri-Drape Wound Edge Protector) was available in three different sizes at each site to enable an appropriate sized device to be selected for the laparotomy wound if the patients was allocated to the intervention arm.

\section{Efficacy outcomes}

The primary endpoint was occurrence of superficial surgical site infection within 30 days after the operation. Diagnosis was based on criteria developed by the Centers for Disease Control (CDC). ${ }^{17}$ All wound assessors were experienced in the appraisal of postoperative wounds and were provided with standardised criteria and instructions regarding assessment. Centralised meetings to update investigators were held throughout the trial, included training in wound assessment, and each unit received a site visit on opening, which included training of local investigators. Additional standardisation of assessment was provided with a dedicated online e-learning module and quiz, developed for this study to minimise variability between assessors.

Secondary endpoints included health related quality of life, length of hospital stay, cost effectiveness, and the clinical efficacy of the device in relation to the degree of contamination, patient comorbidities, and operative demographics. This information was recorded contemporaneously on standardised clinical report forms. 
Data on health related quality of life were collected at baseline, five to seven days, and 30 days with the validated EuroQol (EQ-5D 3L) tool. ${ }^{18}$ Questionnaires were paper based and completed by the patient. The principal analysis was the change in overall health related quality of life assessed by the EQ- $5 \mathrm{D}_{\text {index }}$ score at 30 days. ${ }^{19}$ Data on resource use were collected for 30 days according to a standardised protocol.

\section{Procedures}

Preoperative evaluation included the prospective assessment and recording of demographic data related to the patient and comorbidity. Operative details, including any deviation from allocation, were recorded immediately after the operation.

A trained blinded reviewer formally assessed the wound on day five to seven or at discharge if the patient left hospital earlier. A second formal wound review was performed at 30 to 33 days, which involved the patient returning to hospital for a physical review of the wound. At this same visit, patients also completed a self reported questionnaire with the study investigator to identify any occurrence of surgical site infection during the intervening period between the two clinician assessments. The questionnaire was based on the Health Protection Agency surgical site infection surveillance system (HPA SSISS), which is also based on the original CDC definitions. To maximise completeness of follow-up, trial research staff carried out home visits to the small number of patients who were unable to return to hospital for their second formal wound review because of infirmity or geographical distance.

Investigators who were blinded to the group assignments assessed the seriousness of all reported adverse events and determined if they were related to the study and/or the intervention.

\section{Statistical analysis}

We hypothesised that the use of wound edge protection devices in adults undergoing laparotomy would result in a 50\% reduction in the infection rate based on a conservative appraisal of evidence available from other trials. ${ }^{10}{ }^{11}$ Assuming a conservative baseline infection rate of $12 \%,{ }^{20}{ }^{21}$ we needed 710 patients to confirm this effect with a two sided $\alpha$ of $5 \%$ and $80 \%$ power. The recruitment target was extended to 750 patients to accommodate a potential $5 \%$ dropout rate. Results were analysed according to intention to treat. Analyses were performed with SAS version 9.2 and R Statistical software (v2.14). Dichotomous outcomes (incidence of surgical site infection within 30 days) were analysed with the use of non-linear mixed models, which included stratification variables (plan to open a viscus, create a stoma, and elective $v$ urgent surgery) as patient level covariates and surgeons as random effects. The difference in $\mathrm{EQ}-5 \mathrm{D}_{\text {index }}$ score by treatment group at 30 days was assessed with a mixed model that included baseline $\mathrm{EQ}-5 \mathrm{D}_{\text {index }}$ score and stratification variables as patient level covariates and surgeons as random effects. Time to discharge from hospital was estimated according to the Kaplan Meier method and analysed with the use of Cox proportional hazard model, which included stratification variables as covariates. The initial model was developed in SAS v 9.2, with surgeons subsequently included as random effects with the frailty term in R Statistical Software. Complete case analyses were undertaken for the data on health related quality of life. For those patients who died within 30 days of surgery we carried forward the last available wound assessment, unless no information was available in which case they were treated as lost to follow-up.

\section{Results Study participants}

From February 2010 to January 2012 we enrolled 760 patients from 21 UK centres and randomised 382 to the wound edge protection device group and 378 to the control group (fig 2). $\Downarrow$ Of these, 376 and 373, respectively, underwent laparotomy and were included in the study. Seven patients in each group were subsequently lost to follow-up. Patients' demographics (table $1) \Downarrow$, comorbidities, and operation characteristics (table 2) $\downarrow$, including degree of contamination and NNIS risk index, did not differ substantially between the two groups at baseline.

\section{Surgical site infections}

In total, 184 patients experienced a surgical site infection within 30 days of surgery, $91 / 369(24.7 \%)$ in the device group and $93 / 366(25.4 \%)$ in the control group (odds ratio $0.97,95 \%$ confidence interval 0.69 to $1.36 ; \mathrm{P}=0.85$ ) (table 3 ). $\Downarrow$ The results were consistent across the assessments made at different time points within the study and by different observers, with both the formal assessments of wounds by clinicians and the patients' self reported data showing no difference on post hoc analysis (fig 3) $\Downarrow$. Furthermore, we observed no significant reduction in infection rate within 30 days by treatment group in any of the prespecified subgroup analyses (fig 4). $\Downarrow$

\section{Deviations from protocol and sensitivity analyses}

A wound edge protection device was used in four patients randomised to the control arm and was not used in 29 patients randomised to receive the device: in 11 cases the device was unavailable or of inappropriate size for the procedure, in six cases the nature of the surgery or the peritoneal cavity prevented insertion, in 12 cases the surgical team forgot to use the device. A post hoc sensitivity analysis was undertaken to explore the effect of treatment cross over on the estimate of effectiveness of the device. In this "best case scenario" analysis (in which a maximal benefit from use of device is assumed), all patients allocated to the control group but in whom a device was used were assumed to have had an infection within 30 days, conversely those patients randomised to device use in whom a device was not used were assumed to have had no event. In this extreme case results of the analysis of the effect of the device were still non-significant (odds ratio $0.77,95 \%$ confidence interval 0.54 to $1.09 ; \mathrm{P}=0.14$ ). Further exploratory analyses were also undertaken to assess any potential learning curve effects with use of the device. We found no significant association between the rate of surgical site infection and number of wound edge protection devices used, both at unit and individual surgeon level.

\section{Secondary outcomes}

We observed no significant difference in health related quality of life (mean difference in EQ-5D score $0.001,95 \%$ confidence interval -0.043 to $0.046 ; \mathrm{P}=0.95$ ), and the time to first discharge from hospital was comparable across treatment groups (hazard ratio $1.03,95 \%$ confidence interval 0.88 to $1.19 ; \mathrm{P}=0.82$ ). There were no significant differences in healthcare use between the trial arms in both secondary and primary care settings.

Eleven patients in each group were readmitted to hospital with a surgical site infection, the remaining infections were managed in the community or before discharge from their index admission. 
None of the prespecified secondary analyses exploring the efficacy of the wound edge protection device in reducing the likelihood of infection at the site of surgery according to degree of abdominal contamination, patient comorbidity, duration of surgery, or grade of surgeon closing the wound showed any significant difference (table 2 and fig 4 ). $\downarrow \Downarrow$

\section{Adverse events}

In total 20 patients died within 30 days of surgery (12 in control group; eight in device group). No adverse events associated with the use of the device were reported.

\section{Overall effects of infection at the site of surgery (both arms)}

Patients without an infection had a significantly shorter duration of initial stay in hospital (median days 9 (interquartile range 6-13) in control group and 8 (6-14) in device group) than those with an infection (10 (7-22) and 10 (7-20)).

The 184 patients who developed a surgical site infection consumed significantly more resources in the primary care setting compared with the uninfected patients, reflected in the mean number of interactions with community healthcare professionals (general practitioner, district nurse, practice nurse): mean 8.03 (SE 0.66) in the patients with infection and 3.26 $(0.28)$ in the patients without $(\mathrm{P}<0.001)$. EQ-5D scores also indicated a $11 \%$ reduction in health related quality of life at 30 days in the patients who developed an infection $(\mathrm{P}<0.001)$.

\section{Discussion}

The ROSSINI trial has found that the use of wound edge protection devices during laparotomy does not result in a reduced rate of surgical site infection. This finding was consistent across a range of patient subgroups and for early and late infection. The use of resources, both in hospital and subsequently in the community, was comparable across both arms of the study. These findings differ from results of most previous studies and from two published meta-analyses. ${ }^{22}{ }^{23} \mathrm{Of}$ the previous studies, only two were multicentre and all displayed considerable potential risk of bias. These limitations have been expressed in the expert literature and the need for a large multicentre trial identified. ${ }^{24}$

The reasons behind the variance between the ROSSINI trial and several previous published studies are uncertain. The two previously published multicentre randomised controlled trials reported from a combined total of six units and 270 patients. Nystrom and colleagues, concurring with ROSSINI findings, reported data from 140 patients undergoing elective colorectal surgery at two centres and found no benefit from the use of a device (rate of infection of $10 \%$ in the intervention arm and $9 \%$ in the control group). ${ }^{25}$ More recently, however, Reid and colleagues reported on 130 elective colorectal resections at four Australian centres and found a significant reduction in surgical site infection in the device arm, with 3/64 (4.7\%) developing infection versus $15 / 66(22.7 \%)$ in the control arm $(\mathrm{P}=0.004) .{ }^{15}$ Our trial reported included 760 patients across 21 centres $(62 \%$ colorectal operations) and found no demonstrable benefit for any subgroup of patients.

\section{Strengths and weaknesses}

One concern, particularly in an interventional study, is blinding the assessment to avoid bias. We incorporated several design points to overcome this, including electronic randomisation (including a minimisation procedure), group concealment, blinding of wound assessors and patients, and a robust quality assured follow-up protocol including training in wound assessment. Previous studies of wound edge protection devices have not undertaken all such measures.

The patient groups in our study were well matched with no significant over-representation of any patient or operative characteristic in either arm. At $25.4 \%$, the baseline infection rate was significantly higher than the conservative $12 \%$ predicted baseline rate. This provided increased power to detect potential benefit. Traditionally quoted rates of infection have previously been based on passive and retrospective surveillance and so were prone to under-reporting. The apparent incidence of infection increases significantly, at least doubling in some reports, when outpatient follow-up is undertaken and/or appropriately trained wound observers are used. ${ }^{7-28}$ Recent UK data have reported that the time to onset of infection after gastrointestinal operations is eight to nine days (interquartile range 5-12 days) ${ }^{29}$ and as such will often present after the patient has been discharged from hospital. The higher infection rates (across all sites in our trial) are therefore likely to be related to the policy of more intensive and longer follow-up. Our infection rate is consistent with the rates in several recent studies that also used active wound monitoring and reviews after discharge for colorectal surgery, with reported rates of $25 \%,{ }^{30} 25.3 \%,{ }^{31}$ and $24.9 \% .^{32}$. The fact that the length of hospital stay, use of health resources, and health related quality of life were all significantly and detrimentally affected in patients with a diagnosis of an infection suggests that these patients were truly affected by a condition that impacted on their postoperative recovery and counters the proposition that that the trial processes might have overdiagnosed occurrence of infection at the site of surgery, masking an underlying benefit.

A further notable finding in our trial is the higher than expected infection rate in clean and clean-contaminated operations, which shows little difference to the other contamination groups and is in contrast to routinely presented data. Closer examination of these groups found that the combined infection rate for clean and clean-contaminated patients at the wound review on day five to seven was only $6.5 \%$ (compared with $12.1 \%$ at this stage for the contaminated and dirty wounds). Most infections at the site of surgery in these patients were therefore diagnosed after discharge. This could suggest that the apparently lower infection rates in this group of patients reported elsewhere represent observational bias because of the infections occurring after discharge, perpetuated by patients undergoing these more minor, and often elective, operations having a generally shorter length of hospital stay. In addition, the "clean" operations entailed longer and more complex operations than those typically reported in this category: $32 \%$ underwent adhesiolysis and $12 \%$ incisional hernia repair, which are, by definition "re-do" longer operations and often performed in the acute setting. The overall proportion of clean operations performed as an emergency was $53 \%$. Together these factors might also have contributed to the higher than expected infection rate in this group.

All outcome data have been presented in full for the trial. As per accepted best practice, we primarily undertook an intention to treat analysis, but it is important to also note that the sensitivity analysis did not identify any potential difference in result from treatment cross over.

It is possible that a flaw in the ROSSINI trial has masked a positive result. Key to this is the blinding process, the use of the wound edge protection devices, and the measurement of the endpoint. We instituted an online blinding process in theatre so the patient and wound assessor were unable to introduce bias. We compared the effect of use of the devices in high and low 
recruiting centres and found no difference between the two groups. Finally, the trial has identified a high wound infection rate, which was associated with additional use of health services to manage the wounds. This was, however, entirely equivalent between the two arms, both on the resources used and the timing of the infection treatment. These factors, taken with the large size and multiple centres in the ROSSINI trial would suggest the findings are robust.

\section{How wound edge protection devices might work}

The presumptive primary method of action of the device is that the physical barrier formed by the impervious sheet covering the cut edges of the wound prevents endogenous and exogenous pathogens from coming into contact with the cut skin, fat, and fascia, thereby reducing likelihood of infection. Horiuchi and colleagues presented evidence supporting this theory, showing that these devices seem to protect the incision from bacterial invasion. ${ }^{33}$ It is therefore possible that a protective effect of the device could be real, but the pathogens responsible for surgical site infection could be introduced to the wound when the device is not in place-either on opening the wound before the device is inserted or on closing after the device has been removed. The latter would seem more likely as gloves, instruments, and surroundings will clearly be dirtier. The protocol for our trial did not stipulate changing of gloves, instruments, or drapes, which would not be standard practice in the UK. Evaluation of this practice in combination with a wound edge protection device might be worth considering.

We investigated only the single ring variant of the wound edge protection device. One recent pooled analysis of small single centre studies indicated a difference in outcomes between single ring and two ring devices, but there are no head to head data comparing the different designs. We therefore sought to answer the broader question of the effect of wound edge protection in general, but the suggestion that different device designs might provide greater physical barriers than others could warrant further investigation.

\section{Implications}

Our findings directly challenge the conclusions of numerous smaller scale, largely single centre trials regarding the efficacy of device in reducing surgical site infection. We believe that this outcome is robust and as such feel that practice should change as the routine use of devices in this role cannot be recommended. This trial highlights the need for large scale rigorous and appropriately powered randomised trials to fully assess surgical interventions or devices before their true efficacy can be determined.

\section{ROSSINI Trial steering group}

T Pinkney (chair), D Bartlett, T Mak, H Youseff, G Harrison, W Hawkins, D Morton, S Wilson, M Calvert, G Dowswell, V Redman, R Ryan, L Magill, J Bradbury, M Gill, L Berkman, D Leaper.

Data monitoring committee

J Dunn (chair), J Hill, A Obichere.

Trial administration and site support

J Bradbury, G Dowswell, M Ghods-Ghorbani, R Haslop, V Redman.

Statistical expertise

M Calvert, A Gheorghe, T Roberts.

West Midlands research collaborative committee

D Bartlett, A Bhangu, K Futaba, G Harrison, E Hepburn, S Macleod, T

Mak, P Marriott, P Mistry, T Pinkney, $\mathrm{H}$ Youssef
Trials unit operations group

M Calvert (chair), G Dowswell, V Redman, R Haslop, S Warmington, A Gheorghe.

Local principle investigators

A Kingsnorth (Derriford Hospital, Plymouth); J Hardman (Good Hope Hospital, Sutton Coldfield); D Bowley (Heartlands Hospital, Birmingham); G Carlson (Hope Hospital, Manchester); S Selvaseter, A Khan (Leighton Hospital); A Hamouda (Maidstone Hospital); H Wegstapel (Medway Maritime Hospital); H Youssef (New Cross Hospital , Wolverhampton); S Clarke (Northwick Park, London); A Acheson (Queens Medical Centre, Nottingham); N Hurst (Royal Derby Hospital); P Boorman (Royal Devon and Exeter Hospital); R Patel (Russells Hall Hospital, Dudley); N Cruickshank (Sandwell Hospital); K Siddiqui (Tameside General Hospital, Manchester); R Pullan (Torbay Hospital); D Morton (University Hospital Birmingham); J Lengyel (University Hospital North Staffordshire); R Church (Walsall Manor Hospital); J Francombe (Warwick Hospital); M Paraoan (Wrightington, Wigan and Leigh).

\section{Operating surgeons}

S Aroori, M Bowles, S Brundell, A Kingsnorth, D Stell (Derriford Hospital, Plymouth); M Chapman, T Raju (Good Hope Hospital, Sutton Coldfield); D Bowley, C Hendrickse, S Karandikar, M Richardson, P Super (Heartlands Hospital, Birmingham); I Anderson, G Carlson, N Lees, D Speake, Jonathan Vickers, D Watson (Hope Hospital, Manchester); AU Khan, J Slavin (Leighton Hospital), S Bailey (Maidstone Hospital); S Andrews, W Garrett, P Gandhi, H Wegstapel (Medway Maritime Hospital); I Badger, F Curran, S Elgaddal, T Gardecki, B Isgar, M Manu, R Soulsby, GJ Williams, H Youssef (New Cross Hospital,

Wolverhampton); S Clarke, I Jenkins, R Kennedy, R Phillips (Northwick Park, London); A Acheson, C Maxwell-Armstrong, J Simpson, J Williams (Queens Medical Centre, Nottingham); N Hurst, S Y Iftikhar, M Larvin, J Lund, J Quarmby, J Reynolds, W Speake, G Tierney (Royal Derby Hospital); P Boorman, I Daniels, S Mansfield (Royal Devon and Exeter Hospital); A Jayatunga, A Kawesha, S Macleod, R Patel, R Pathak, A Rehman, A Savage, C Sellahewa, P Stonelake (Russells Hall Hospital, Dudley); N Cruickshank, K Gill, E Harper, H Joy, V Laloe, M Mirza, D Mobarak, M Sintler, V Thumbe, M Vairavan, K Wheatley (Sandwell Hospital); A Benhamida, K Siddiqui, M Solkar (Tameside General Hospital, Manchester); R Pullan (Torbay Hospital); O Adedeji, S Bach, D Gourevitch, T Ismail , C Keh, M Midwinter, D Morton, S Radley, N Suggett (University Hospital Birmingham), D Beardsmore, C Cheruvu, W Crisp, F Curran, R Dawson, M Deakin, D Durkin, M Farmer, R Kirby, J Lengyel (University Hospital North Staffordshire); R Church (Walsall Manor Hospital); K Busby, J Francombe, P Murphy, M Osborne (Warwick Hospital); A Azmi, A Blower, M Haque, R Harland, S Loganathan, N Mackenzie, M Paraoan (Wrightington, Wigan and Leigh).

Local investigators and wound reviewers

M Bowles, P Brockmann, F Coates, P Eardley, M Gavasingha, S Hornby, B Hyam, C Meachin, M Napier, A Page, S Price, S Read (Derriford Hospital, Plymouth); L Hanna, A Torrance, H Youssef (Good Hope Hospital, Sutton Coldfield); D Bowley, P Calderbank, W Hawkins, C Horrobin, A Munasinghe, S Nachrauthu, R Nandra (Heartlands Hospital, Birmingham); J Barker, E Barrow, C Downes, J Epstein, A Keen, V Shetty, D Speake, M Taylor (Hope Hospital, Manchester); V Adamson, C Hough, A Khan, C Mansfield, O Oshin (Leighton Hospital); J Bedo, R Einosas, A Hamouda, S Jones, L Tomlinson, A Wadoodi (Maidstone Hospital); T Akinola, R Casey, T Cumming, H Dent, R Evans (Medway Maritime Hospital); H Ali, S Ashraf, T AuYong, N Battersby, G Bonney, H Cheng, H Coop, H Cooper, S Dhanda, S Dhillon, S Elgaddal, C El-sayed Fi, M Green, J Long, G Markam, M Mascarentros, D McArthur, J Mohammed, S Pickering, T Pinkney, A Quigley, S Raichura, E Rahman, N Raza, C Richardson, S Roy, H Roberts, S Sahdev, T Sein, A Sharples, R Soulsby, M Treece, M Whitehouse, A Wong, H Youssef (New Cross Hospital , Wolverhampton); G Bashir, C Beaton, G Lee, G Rahbour, D Ramgoolam, S Rasheed, S Sakuma, S Sherman, C Thorn, 


\section{What is already known on this topic}

Two systematic reviews have pooled multiple small randomised controlled trials exploring the use of wound edge protection devices to reduce surgical site infections after abdominal surgery and suggested an overall beneficial effect

\section{What this study adds}

Wound edge protection devices do not reduce rate of surgical site infection, health related quality of life, or length of stay in hospital compared with standard care

S Wright (Northwick Park, London); E Barnes, D Humes, J Lynch, M Lythgoe, J Simpson, C Walter, K Ward (Queens Medical Centre, Nottingham); S Aggrawal, C Boereboom, E Collins, E Elsey, A Hall, S Hamandishe, L Kimber, O Peacock, S Pyke, D Reeves, J Smith, E Stobbs, N Watson (Royal Derby Hospital); S Harvey, R James, S Mansfield, Y Nijs, M Wiggins (Royal Devon andExeter Hospital); J Bate, A Bhangu, T Jennson, P Marriott, K McNamara, J Royle, P Singh, M Tan, J Walton, J Wheeler, L Wright, N Yassin (Russells Hall Hospital, Dudley); T Baldwin, M Ballentine, A Bhangu, C Bell, A Beveridge, J Carter, J Chrickshank, J Colley, D Cox, N Cruickshank, N Cutmore, J Dasgin, K Davis, M Dixon, J Doyle, A Dudley, G Fisher, H Fletcher, F Fuerstenberg, B Gammon, C Garbutt, K Goonetilleke, D Harji, H Harper, J Harvey, L Henderson, I Jenkins, A John, P Kaur, P Marriott, S Poxon, C Parkes, D Pugh, L Rhodes, K Richardson, M Roper, V Rusius, B Sharip, J Smith, S Todd, B Turner, D Vijayan, M Wakewal, R Walker, K Wheatley, L Williams (Sandwell Hospital); S Cocks, E Curran, S Ridgway (Tameside General Hospital, Manchester); B George, A Hall, P Mercer, $\mathrm{H}$ Thatcher, J Watson (Torbay Hospital); D Bartlett, S Baijal, J Bradbury, M Coakes, L Crutch, H Edgar, K Futaba, P Guruswamy, A Leyland, N Mabena, T Mak, K Manan, N Manimaran, N Markarian, R Melhado, J Millington, N Mirza, D Mittapalli, A Munasinghe, M Naqvi, S Pandey, T Pinkney, S Ramcharan, R Ravikumar, L Ryder, G Sahota, C Wearn, M White, K Wong (University Hospital Birmingham); S Bahia, D Beardsmore, C Bloom, N Briscoe, P Casey, S Dawson, M Deakin, M Denning, M Dennis, A Durber, M El-Shaeib, J Evans, L Fellows, S Hoswell, J Jackson, T Jones, M Lakhan, S Lord, W Hawkins, D Monnery, P Patel, F Rafati, M Reabin, E Rylands, O Sharifi, L Stevenson, F Tomlins (University Hospital North Staffordshire); R Church, A Kitchen, A Puligari, J Sidebotham, E Swan, A Tilley, L Wagstaff (Walsall Manor Hospital); J Barnes, L Clare, K Dasari, S Fallis, J Francombe, E Foster, K Futaba, E Leung, M McFarlane, S Rastall, N Silvey, G Waight, L Whisker (Warwick Hospital); M Antony, A Ahmed, S Baxendale, Y Chandler, M Corfield, Y Dunn, T Edwardson, N Fairclough, R Hodgkins, J Hughes, K Humayun, V Kaliyaperumal, S Lawton, J Leary, S Loganathan, N Mackenzie, M McDermott, M Paraoan, D Paterson, L Pender, P Prasad, J Smith, C Spence, L Roberts, A Robinson (Wrightington, Wigan and Leigh).

Funding: This study was funded by NIHR; Research for Patient Benefit programme (PB-PG-1208-18234). Wound edge protection devices were provided free of charge by $3 \mathrm{M}$ (Bracknell, UK), who also hosted the online e-learning module and quiz. Representatives from $3 \mathrm{M}$ did not sit on the trial management group and had no input in trial design, data collection, data analysis, or manuscript synthesis.

Contributors: TP, MC, DB, AG, GD, WH, TM, HY, LM, SW, and DM participated in the study design. HY, TP, TM, WH, LM, MC, DB, DL, SW, and DM obtained funding for the study. VR and RH collected the data. VR was trial manager. $M C$ and $A G$ analysed the data and provided methodological and statistical expertise. AG led the health economics analysis with support from MC, TR, TP and DB. TP, DM, MC, AG, and $\mathrm{DB}$ drafted the report, and the report was revised for important intellectual content by all authors. TP, MC, DB, AG, and DM are guarantors.

Competing interests: All authors have completed the ICMJE uniform disclosure form at www.icmje.org/coi_disclosure.pdf (available on request from the corresponding author) and declare: no support from any organisation for the submitted work; no financial relationships with any organisations that might have an interest in the submitted work in the previous three years; no other relationships or activities that could appear to have influenced the submitted work.

Ethical approval: The protocol ${ }^{16}$ was approved by the national research ethics service (09/H1204/91; North Staffordshire committee) and the research and development team at each hospital. Written informed consent was obtained from all patients before enrolment.

Data sharing: Statistical analysis plan and anonymised dataset available from to bona fide researchers on request from the corresponding author. A data transfer agreement will need to be completed. Consent was not obtained from participants for data sharing, but the presented data are anonymised and risk of identification is low.

1 Smyth ET, Mcllvenny G, Enstone JE, Emmerson AM, Humphreys H, Fitzpatrick F, et al. Four country healthcare associated infection prevalence survey 2006: overview of the results. J Hosp Infect 2008;69:230-48.

2 Bruce J, Russell EM, Millinson J, Krukowksi ZH. The measurement and monitoring of surgical adverse events. Health Tech Assess 2001;5:1-194.

3 Mangram AJ, Horan TC, Pearson ML, Silver LC, Jarvis WR. Guideline for prevention of surgical site infection, 1999. Centers for Disease Control and Prevention (CDC) Hospital Infection Control Practices Advisory Committee. Infect Control Hosp Epidemiol 1999;20:250-78.

4 Wilson AP, Gibbons C, Reeves BC, Hodgson B, Liu M, Plummer D, et al. Surgical wound infection as a performance indicator: agreement of common definitions of wound infection in 4773 patients. BMJ 2004;329:720-4.

5 Coello R, Charlett A, Wilson J Ward V, Pearson A, Borriello P. Adverse impact of surgical site infections in English hospitals. $J$ Hosp Infect 2005;60:93-103.

6 Plowman R, Graves N, Griffin MA, Roberts JA, Swan AV, Cookson B, et al. The rate and cost of hospital-acquired infections occurring in patients admitted to selected specialities of a district general hospital in England and the national burden imposed. J Hosp Infect 2001;47:198-209.

7 Tanner J, Khan D, Aplin C, Ball J, Thomas M, Bankart J. Post-discharge surveillance to identify colorectal surgical site infection rates and related costs. $J$ Hosp Infect 2009;72:243-50

8 Perencevich EN, Sands KE, Cosgrove SE, Guadagnoli E, Meara E, Platt R. Health and economic impact of surgical site infections diagnosed after hospital discharge. Emerg Infect Dis 2003:9:196-203.

9 Redmond HP, Meagher PJ, Kelly CJ, Deasy JM. Use of an impervious wound-edge protector to reduce the postoperative wound-infection rate. Br J Surg 1994;81:1811.

10 Sookhai S, Redmond HP, Deasy JM. Impervious wound-edge protector to reduce postoperative wound infection: a randomised, controlled trial. Lancet 1999;353:1585.

11 Horiuchi T, Tanishima H, Tamagawa K, Matsuura I, Nakai H, Shouno Y, et al. Randomized, controlled investigation of the anti-infective properties of the Alexis retractor/protector of incision sites. J Trauma 2007:62:212-5.

12 Lee P, Waxman K, Taylor B, Yim S. Use of wound-protection system and postoperative wound-infection rates in open appendectomy - a randomized prospective trial. Arch Surg 2009;144:872-5.

13 Theodoridis T, Chatzigeorgiou K, Zepiridis L, Papanicolaou A, Vavilis D, Tzevelekis F et al. A prospective randomized study for evaluation of wound retractors in the prevention of incision site infection after caesarean section. Clin Exp Obstet Gynecol 2011:38:57-9.

14 Cheng KP, Roslani AC, Sehha N, Kueh JH, Law CW, Chong HY, et al. ALEXIS O-Ring wound retractor vs conventional wound protection for the prevention of surgical site infections in colorectal resections. Colorectal Dis 2012;14:e346-51.

15 Reid K, Pockney P, Draganic B, Smith SR. Barrier wound protection decreases surgical site infection in open elective colorectal surgery: a randomized clinical trial. Dis Colon Rectum 2010;53:1374-80.

16 Pinkney TD, Bartlett DC, Hawkins W, Mak T, Youssef H, Futaba K, et al. Reduction of surgical site infection using a novel intervention (ROSSINI): study protocol for a randomised controlled trial. Trials 2011;12:217.

17 Horan TC, Andrus M, Dudeck MAC. DC/NHSN surveillance definition of healthcare-associated infection and criteria for specific types of infections in the acute care setting. Am J Infect Control 2008:36:309-32.

18 Brooks R, de Charro F. EuroQol: the current state of play. Health Policy 1996:37:53-72.

19 Dolan P. Modeling valuations for EuroQol health states. Med Care 1997;35:1095-108.

20 Health Protection Agency. Surveillance of surgical site infection in England: October 1997-September 2005. Health Protection Agency, July 2006.

21 Song F, Glenny AM. Antimicrobial prophylaxis in colorectal surgery: a systematic review of randomised controlled trials. Br J Surg 1998;85:1232-41.

22 Gheorghe A, Calvert M, Pinkney TD, Fletcher BR, Bartlett DC, Hawkins WJ, et al. Systematic review of the clinical effectiveness of wound-edge protection devices in reducing surgical site infection in patients undergoing open abdominal surgery. Ann Surg 2012;255:1017-29.

23 Edwards JP, Ho AL, Tee MC, Dixon E, Ball CG. Wound protectors reduce surgical site infection-a meta-analysis of randomized controlled trials. Ann Surg 2012;256:53-9.

24 Barie PS. Does a well-done analysis of poor-quality data constitute evidence of benefit? Ann Surg 2012;255:1030-1. 
25 Nyström PO, Broome A, Hojer $\mathrm{H}$, Ling L. A controlled trial of a plastic wound ring drape to prevent contamination and infection in colorectal surgery. Dis Colon Rectum 1984;27:451-3.

26 Ferraz EM, Ferraz AA, Coelho HS, Pereira Viana VP, Sobral SM, Vasconcelos MD, et al. Postdischarge surveillance for nosocomial wound infection: does judicious monitoring find cases? Am J Infect Control 1995;23:290-4.

27 Petherick E, Dalton J, Moore P, Cullum N. Methods for identifying surgical wound infection after discharge from hospital: a systematic review. BMC Infect Dis 2006;6:170.

28 Miransky JRL, Nicoletta S, Eagan J, Eagan J, Sepkowitz K, Margetson N, et al. Impact of a surgeon trained observer on accuracy of colorectal surgical site infection rates. Dis Colon Rectum 2001;44:1100-5.

29 Health Protection Agency. Surveillance of surgical site infections in NHS hospitals in England, 2010/2011. Health Protection Agency, December 2011.

30 Blumetti J, Luu M, Sarosi G, Hartless K, McFarlin J, Parker B, et al. Surgical site infections after colorectal surgery: Do risk factors vary depending on the type of infection? Surgery 2007;142:704-11.

31 Howard DPJ, Datta G, Cunnick G, Gatzen C, Huang A. Surgical site infection rate is lower in laparoscopic than open colorectal surgery. Colorectal Dis 2010;12:423-7.
32 Serra-Aracil X, Garcia-Domingo MI, Pares D, Espin-Basany E, Biondo S, Guirao X, et al. Surgical site infection in elective operations for colorectal cancer after the application of preventive measures. Arch Surg 2011;146:606-12.

33 Horiuchi T, Tanishima H, Tamagawa K, Sakaguchi S, Shono Y, Tsubakihara H, et al. A wound protector shields incision sites from bacterial invasion. Surg Infect (Larchmt) 2010;11:501-3.

Accepted: 27 June 2013

\section{Cite this as: BMJ 2013;347:f4305}

This is an Open Access article distributed in accordance with the Creative Commons Attribution Non Commercial (CC BY-NC 3.0) license, which permits others to distribute, remix, adapt, build upon this work non-commercially, and license their derivative works on different terms, provided the original work is properly cited and the use is non-commercial. See: http://creativecommons.org/licenses/by-nc/3.0/. 


\section{Tables}

Table 1 | Characteristics of patients undergoing laparotomy with and without use of a wound edge protection device (WEPD). Figures are numbers (percentage) of patients unless specified otherwise

\begin{tabular}{lcc} 
Characteristic & WEPD $(\mathbf{n}=\mathbf{3 7 6})$ & Control (n=373) \\
Median (IQR) age (years) & $66.4(54.8-74.7)$ & $64.2(55.5-72.8)$ \\
\hline Men & $200(53.2)$ & $193(51.7)$ \\
\hline Median (IQR) BMI & $26.5(23.1-30.0)$ & $26.0(23.1-29.1)$ \\
\hline Median (IQR) serum albumin concentration & $41.0(34.0-44.0)$ & $40.0(35.0-44.0)$ \\
\hline Diabetes & $62(16.5)$ & $51(13.7)$ \\
\hline Current smoker & $64(17.0)$ & $57(15.3)$ \\
\hline Known ongoing malignancy at any site & $241(64.1)$ & $241(64.6)$ \\
\hline Median (IQR) baseline EQ-5D* & $0.81(0.69-1)$ & $0.85(0.73-1)$ \\
\hline Urgency of operation: & & $183(49.1)$ \\
\hline Elective & $181(48.1)$ & $117(31.4)$ \\
\hline Expedited & $117(31.1)$ & $71(19.0)$ \\
\hline Urgent & $75(20.0)$ & $2(0.5)$ \\
\hline Immediate & $3(0.8)$ & $49(13.1)$ \\
\hline ASA grade: & $36(9.6)$ & $186(49.9)$ \\
\hline 1 & $203(54.0)$ & $95(25.5)$ \\
\hline 2 & $113(30.1)$ & $7(1.9)$ \\
\hline 3 & $4(1.1)$ & $1(0.3)$ \\
\hline 4 & $0(0.00)$ & $35(9.4)$ \\
\hline Unknown & $20(5.3)$ &
\end{tabular}

$\mathrm{IQR}=$ interquartile range, $\mathrm{BMI}=$ body mass index, $\mathrm{EQ}-5 \mathrm{D}=\mathrm{E}$ uroQol health related quality of life score, $\mathrm{ASA}=\mathrm{American}$ Society of Anaesthesiologists. ${ }^{*}$ Measured in 359 in WEPD group and 351 in control group. 
Table 2| Procedural characteristics in patients undergoing laparotomy with and without use of a wound edge protection device (WEPD). Figures are numbers (percentage) of patients unless specified otherwise

\begin{tabular}{|c|c|c|}
\hline Characteristic & WEPD $(n=376)$ & Control $(n=373)$ \\
\hline \multicolumn{3}{|l|}{ Operation site: } \\
\hline Large bowel & $247(65.7)$ & $237(63.5)$ \\
\hline Small bowel & $34(9.0)$ & $48(12.9)$ \\
\hline Hepatobiliary & $77(20.5)$ & $72(19.3)$ \\
\hline Gastric & $15(4.0)$ & $8(2.1)$ \\
\hline Cholecystectomy & $1(0.3)$ & $2(0.5)$ \\
\hline Vascular & $1(0.3)$ & 0 \\
\hline Abdominal hysterectomy & 0 & $2(0.5)$ \\
\hline Unknown & $1(0.3)$ & $4(1.1)$ \\
\hline Stoma created & $109(29.0)$ & $106(28.4)$ \\
\hline \multicolumn{3}{|l|}{ Skin prep used: } \\
\hline Chlorhexidine & $136(36.2)$ & $135(36.2)$ \\
\hline Aqueous Betadine (povidone-iodine) & $215(57.2)$ & $197(52.8)$ \\
\hline Alcoholic Betadine (povidone-iodine) & $16(4.3)$ & $29(7.8)$ \\
\hline Towels/mops used on wound edges & $42(11.2)$ & $78(20.9)$ \\
\hline \multicolumn{3}{|l|}{ Degree of contamination: } \\
\hline Clean & $24(6.4)$ & $31(8.3)$ \\
\hline Clean-contaminated & $275(73.1)$ & $268(71.9)$ \\
\hline Contaminated & $48(12.8)$ & $48(12.9)$ \\
\hline Dirty & $29(7.7)$ & $25(6.7)$ \\
\hline Median (IQR) duration of surgery (h) & $3.0(2.0-4.0)$ & $2.73(2.0-4.0)$ \\
\hline Median (IQR) NNIS index* & $1(0-1)$ & $1(0-1)$ \\
\hline \multicolumn{3}{|l|}{ Prophylactic antibiotic given: } \\
\hline On induction & $321(85.4)$ & $322(86.3)$ \\
\hline During procedure & $25(6.7)$ & $18(4.8)$ \\
\hline \multicolumn{3}{|l|}{ Grade of operating surgeon: } \\
\hline Consultant & $302(80.3)$ & $280(75.1)$ \\
\hline Trainee & $69(18.4)$ & $82(22.0)$ \\
\hline \multicolumn{3}{|l|}{ Grade of surgeon closing fascia: } \\
\hline Consultant & $186(49.5)$ & $197(52.8)$ \\
\hline Trainee & $182(48.4)$ & $157(42.1)$ \\
\hline
\end{tabular}


Table 3| Primary and secondary endpoints in patients undergoing laparotomy with and without use of a wound edge protection device (WEPD). Figures are numbers (percentage) of patients unless specified otherwise

\begin{tabular}{|c|c|c|c|c|}
\hline Outcome & WEPD & Control & Estimate $(95 \% \mathrm{Cl})$ & $P$ value \\
\hline \multicolumn{5}{|l|}{ Primary outcome } \\
\hline Surgical site infection (SSI) within 30 days & $91 / 369(24.7)$ & $93 / 366(25.4)$ & $0.97^{*}(0.69$ to 1.36$)$ & 0.85 \\
\hline \multicolumn{5}{|l|}{ Secondary outcomes } \\
\hline Mean (SD) EQ-5D & $0.69(0.29) \dagger$ & $0.69(0.30) \ddagger$ & $0.001 \S(-0.04$ to 0.05$)$ & 0.95 \\
\hline Median (IQR) length of hospital stay (days) & $9(6$ to 15$)$ & $9(6$ to 14$)$ & $1.039(0.88$ to 1.19$)$ & 0.82 \\
\hline \multicolumn{5}{|l|}{ Degree of wound contamination: } \\
\hline Clean & $8 / 24(33.3)$ & $7 / 29(24.1)$ & $1.76^{*}(0.40$ to 7.70$)$ & 0.43 \\
\hline Clean-contaminated & $61 / 269(22.7)$ & $63 / 263(24.0)$ & $0.94^{*}(0.62$ to 1.42$)$ & 0.76 \\
\hline Contaminated & $10 / 48(20.8)$ & $15 / 48(31.3)$ & $0.601^{*}(0.23$ to 1.63$)$ & 0.31 \\
\hline Dirty & $12 / 28(42.9)$ & $7 / 25(28.0)$ & $1.85^{*}(0.50$ to 6.87$)$ & 0.33 \\
\hline $\begin{array}{l}\text { IQR=interquartile range, EQ-5D= EuroQol } \mathrm{h} \\
{ }^{\star} \text { Odds ratio. } \\
\dagger \mathrm{\dagger n}=318 . \\
\ddagger \mathrm{fn}=313 . \\
\text { §Difference in means. } \\
\text { ॠHazard ratio. }\end{array}$ & nealth related qu & uality of life scor & & \\
\hline
\end{tabular}




\section{Figures}

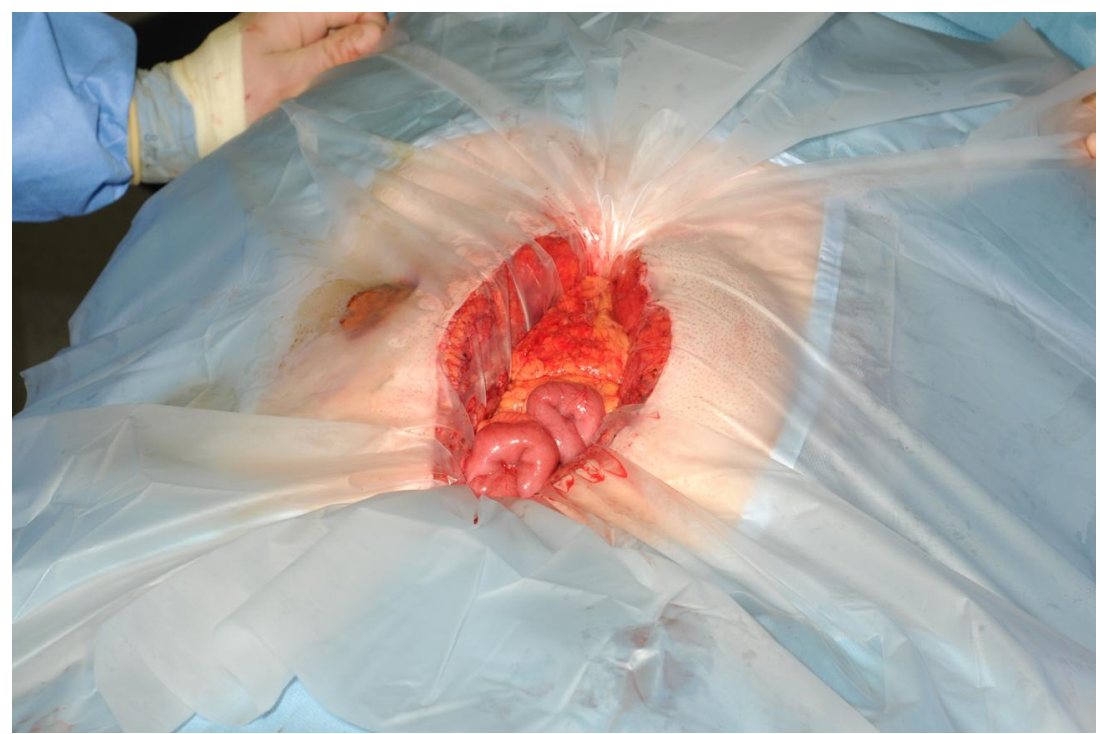




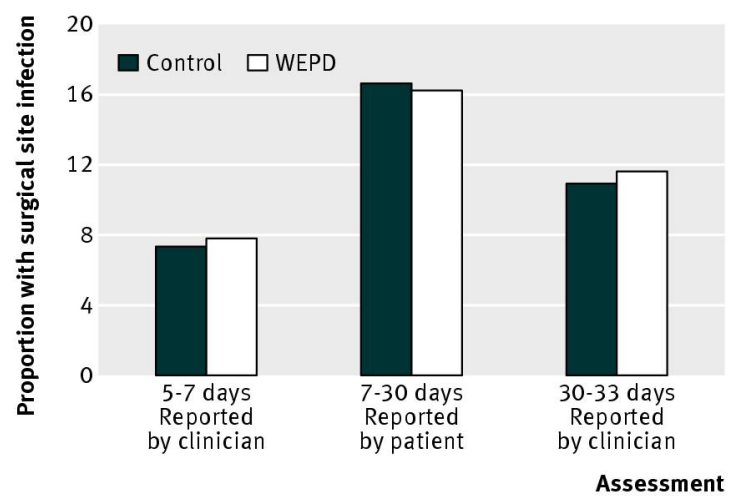

Fig 3 Rates of surgical site infection by treatment group within 30 days in patients allocated to surgery with use of wound protection device (WEPD) or standard care 


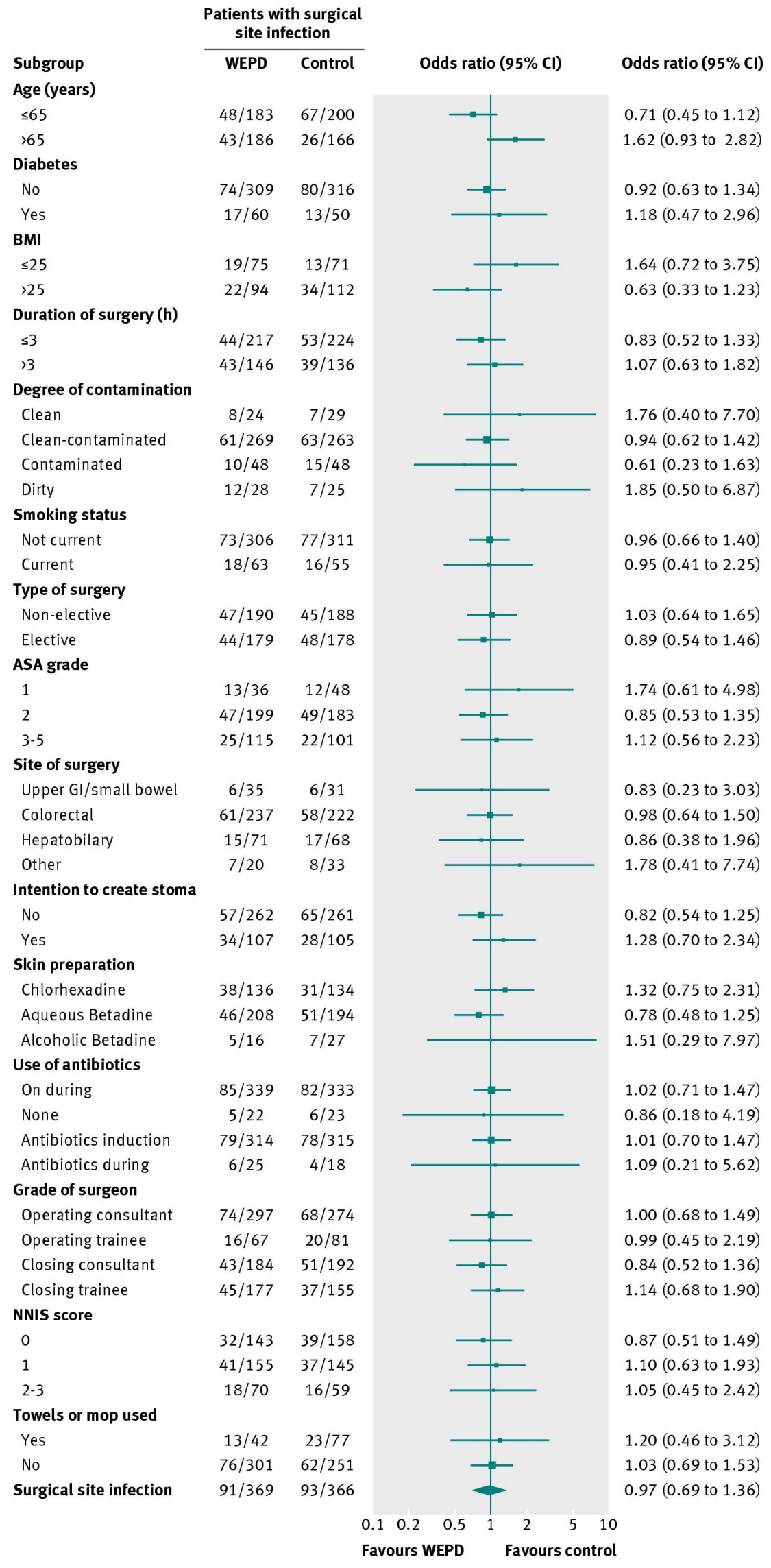

Fig 4 Subgroup analyses for primary outcome in patients allocated to surgery with use of wound protection device (WEPD) or standard care 